Setvicio de Otorrinolaringologia

del Hospital Arriarán.

Jefe: Dr. Marcial Farada.

\title{
DIAGNOSTICO Y TRATAMIENTO DE LAS DISNEAS AgUDAS LARINGO-TRAQUEALES DE LA INFANCIA
}

\author{
Por el Dr. AUgUSTO LATORRE AGUERO
}

La colaboración del otorrinólogo en la práctica pediátrica es je gran va!or para el diagnóstico y tratamiento del numerosas afecciones de la infancia. Erta colaboración, seguramente, en ningún capítulo de la patología infantil es tan decisiva e importante como ante un cuadro de disnea aguda latingo-traqueal. Sin embargo, entre nosotros, ocurre el hecho paradojal que ante un caso de esta naturaleza, rara vez el peldiatra consulta al otorrinólogo. Es una cosa corriente. de rutina. que se nos pida nuestro concurso para investigar una posible otitis en un lactante que padece de un trastorno nutritivo o que presenta un cuadro infeccioso indeterminado. - para hacer un examen faringeo ante una nefritis o cardiopatia, etc., pero ante un niño en peligro de asfixia por una disnea aguda laringo-traqueal; al pediatra basándose únicamente en la historia clínica y resultado de su. examen, por lo general, hace el dagnóstico e instituye el tratamiento sin solicitar nuestra opinión para nada. El diagnóstico clínico en estos casos tiene un gran margen de error y en cambio, el otorrinólogo cuenta en este sentido, tanto para el diagnóstico como para el tratamiento, con recursos del enorme valor, como veremos en el curso de esta exposición. 
I. Generalidades acerca de la disnea aguda laringo-traqueal.

La disnea aguda laringo-traqueal es un cuadro muv frecuente en la práctica infant: y cuyo diagnóstico causa! y tratamidnto, debe hacerse siempre con carácter de suma urgen. cia, puesto que en la inmensa mayoría de los casos significa un gravísimo peligro para la vida del pequeño paciente.

La disnea laringo-traquea! es siempre una disnea mecánica por obstrucción parcial de la laringe o de la porción cervical de la tráquea, ya sea debido a espasmos, edema, cuerpos extraños. pseuciomembranas, secreciones, etc. 'Se comprendel entonces que sea más frecuente en los niños pequeños, menores de cinco años generalniente.

El sintoma capital de este tipo de disnea y que por sí solo hace el diagnóstito de disné taringo-traqueal, es el tiraje. Este se presenta bajo la forma de una retracción inspiratoria de la fosa supraesternal y fosas supraclavicu'ares, e incluso del epigastrio y espacios intercostales, con descenso ce la laringe en cada inspiración.

El tiraje se debe a la presión negativa producida por la expansión inspiratoria del tórax estando la tráquea o laringe parcialmente obstruídas: lo que hace que se produzca la rotracción de las partes blandas que no están sostenidas por huesos o cartílagos. Este signo to se observa en las disneas pulmonares o cardiacas, a menos que haya una complicación laríngea.

La dísnea laringo-traqueal puede ser aguda o crónica. Nosotros nos ocuparemos solamente de la forma aguda que es la más común en la infancia, ya que la forma crónica es propia de! adulto.

Una vez becho el diagnóstico de disnea aguda laringotraqueal debemos establecer inmediatamente la causa de la: disnea y el sitio de 13 obstrucción.

II. Cansas de las disneas agudes laringo-traqueales.

En la práctica, las tres grandes causas productoras de este tipo de disnea son: los cuerpos extraños laringo-traqueales, la difteria de la laringe y las laringitis agudas.

A. Cuerpos extraños laringo-traqueales.-Aunque son una causa poco frecuente de disnea aguda laringo-traqueales; nunca debemos dejar de pensar en esta posibilidad ante un caso de disnea laringo-traqueal de aparición brusca. 
La introducción de un cuerpo extraño en la laringe provoca siempre, de inmediato, un violento accetso de tos y de sofocación. La cara se congestiona; los ojos se inyectan; puede sobrevenir cianosis y asfixja. En resumen, e! cuadro es siempre impresionante.

Si el cuerpo extraño es muy voluminoso puede cteterminar la muerte por asfixia ráp damente; pero, por lo general, este accidente no es de tanta gravedad y el cuerpo extraño es expulsado en medio de violentos accesos de tos, o desciende hacia los bronquios, pasando el peligto inmediato de asfixia, o bien so enclava en la laringe.

Los síntomas son función del volumen y șituación dẹl cuerpo extraño.

La disnea depende del grado de obstrucción y del espasmo que siempre sel agrega ent tales momentos.

La tos es un signo casi constante y es provocada pot la irritación de la mucosa laríngea, producida por el cuerpo extraño. Esta tos puede ser ronea, quiritosa o de carácter crupal.

'Si el cuerpo extraño sel sitúa entre las dos cuerdas vocales, produce una afonía total. Si sitúa por debajo de las cuerdas la voz puede estar clara al principio, aunque rápidamente aparece después ronquera por laringitis inflamatoria secundar:a.

Si la forma dell cuetpo extraño es itregular y tiene aristas cortantes, provoca dolores espontáneos y a la deglución, e incluso, pequeñas hemorragias. Cuando es móvil dentro de la latinge, determina una respiración sibilante acompañada de un ruido de válvula o "de bandera", que es patognomónico.

B. La difteria latíngea.-Evito emplear aquí la palabra "crup", porque es un término que se presta a confusiones. "Crup". para los franceses (Canuyt. Lel Mée, etc.) significa difteria latíngea obstructiva; por esto los tratados en esta lengua nos hablan de "crup" y de "falsos crups". En cambio los norteamericanos (Orton, Smith, Be1l, Ford, etc.) llaman "crup" a toda disnea aguda laringo-traqueal sin especificar su naturaleza, y así, distinguen el "crup diftérico". el "crup catarral", el "crup espasmódico", etc. Entre nosotros los pediatras usan tanto la nomenclatura francesa como la americana, por eso, para evitar malentendidos, es preferible prescindir de la palabra "crup".

El cuadro clínico de la difteria laríngea es de todos astedes demasiado conocido para que yo insista mayormente en él. 
Se trata, por lo general, de un niño de dos a cinco años (rara vez de un lactante), que empeza a tener tos seca, tonquera, elevación térmica moderada; pronto la voz se hace sorda y velada, y por Gitimo se extingue por completo. En este momento, esto es al segundo o.tercer día de enfermedad, ha aparecido ya una ligera disnea quel va en aumento rápidamente. La inspiración se hace más difícil y laboriosa; la expiración es prolongada y silbante. Estos síntomas se agravan por momentos $y$ se constata tiraje supraesternal y epigástrico, cianosis, etc.

Prácticamente la difteria laríngea es siempre secundoria a una difteria faríngea o rinofaríngea. La difteria primitiva de la laringe es rara; mucho más rara de lo que suponen los pediatras que siempre la diagnostican con excesiva trecuencia y etrónemente, como veremos más adelante.

C. Las latingitis agudas de la infancia.-Las laringitis agudas son muy frecuentes en la infancia. Esta frecuencia se debe a diversos factores: abundancia de tejido acenoídeo rinofaringeo, muchas veces crónicamente infectado $y$ cuya inflamación repercuter a menudo sobre la laringe: presencia de téiido linfoídeo en la laringe que tiende a localizar la infección $v$ frecuencia de las enfermejades infecciosas en la infancia (fièbres eruptivas, etc.).

La gravedad de estas laringitis se debe a los caracteres anatómicos particulares de la laringe infantil. La cavidad laríngea de los niños, especialmente lactantes, es muy estrecha. Por otrá parţe, la región subglótica presenta algunas características especiales. La mucosa en esta zona es muy laxa y se deja infiltrar fácilmente por el edema; existen a este nivel numerosos folícu!os linfát cos y además, es esta una zona hiperéstésica y reflexógena. La excitación de la mucosa laringea (cuerpo extraño, proceso infeccioso, etc.) llega al bulbo por intermedio del nervio laríngeo superior y por la vía del nervio espinal, delsencadena un espasmo de la laringe. De aquí que una simple laringitis edematosa banal pueda provocar un cuadro alarmante de obstrucción aguda laríngea.

Estas laring tis pueden ser primitivas o secundarias a una infección de vecindad (coriza. amigdalitis, adenoiditis, etc.); o bien. pueden presentarse en el curso de una enferme- . dad genelral como grippe. fiebres eruptivas, etc.

Como causa predisponente importante están las adenoiditis y am:gdalitis .crónicas. En cuanto a la causa determinante de estas laringitis, es siempre de naturaleza infecciosa. 
Se trata ya de infecciones monomicrobianas o, lo que es más frecuente, de infecciones polimicrobianas. Los gérmenes generalmente encontrados son el estreptococo, estafilococo o pneumococo.

El frío parece jugar un rol importante en la localización de la infección a nivel ée la laringe.

Entre las numerosas clasificaciones existentes de las laringitis agudas del. la infancia, muy buena nos parece la de Le Mée, Bloch y Bouchet, por su sencillez y claridad. Estos autores dividen las laringitis agudas de la infancia basándose en la distribución topográfica de las lesiones y distinguen las siguientes formas clínicas:

1. Laringitis supragtóticas. Son las laringitis banales qué, clínicamente, se caracterizan sólo por tos seca y ronquera; son a menudo afebriles y de pronóstico benigno.

Las iesiones, en estos casos, consisten en hiperemia de las cuerdas vocales $\mathrm{y}$ discreta tumefacción de las bandas ventriculazes o falsas cuerdas. En este tipo de laring tis no hay disnea ni tiraje salvo si se produce un edema muy intenso o un flegmón de las bandas ventriculares o de la región aritenoidea, lo que en los nirios es exceptional.

Un ejemplo típico del laringitis supraglót ca bànal es la siguiente observación:

OBSERVACION N." 1. - Merced:s J.. + años đe edad. Ficha $\mathbf{8 0 3 8 5}$ de! Hospita? Arriarán.

Antecedentes heradiparios y personzles. -.. Sin importancia.

Enfermedad actual. - Se inicia hace cuatto dias con ronquara progrestipa $y$ tos perrana, sin otras molrstias. La madre. alarmada. la lleva ia la. Posta Infantil del. Hospital Artiaśn, en donde el médien de guatlia. impresionado por la ronquera y caracteres de li tos, le hace colocar 20,000 unidades de suero antidiftérico y la envia al die siguiente a nuestro sezvicio.

Al examen nos encestramos con una niña de 4 años, con buen estado genetal. Afebril. Voz mup renca. pero no hay distea ni tiraje supraesternal. El examen faríngo es negativo y al examen naial constatamos solamente una sinitis aguda catarral. Al examen laringes tbecho por laringostopia dimeta) comprobamos lo siguiente: ligera infilración de las blandas ventriculares; cuerdas' vacales hipeténicas. de movilidad normal: no hay pendomembranas ni vlceraciones: negión subglótica y ttáquea, nacia especial.

Diegnóstico. - Laringitis supraglótica banal.

El examen bacteriológico de la secreción laringea no reveló, posteriocmente, la existencia de bacilos de Loeffler. 
2. Laringitis subglóticas benignàs.-Este grupo comprende las laringitis estridulosas. La lesión se localiza en la subglotis y consiste en un edema muy poco pronunciado $y$ pasajeto. El espasmo juega en estos casos el rol principal.

El cuadro clínico es característico; principio brusco en r.n niño de 2 a 5 años, con tos ronca y disnea intensa con los caracteres ge obstrucción laringo-traqueal. La voz está modificada en su timbre: ronca pero no apagada como en la difteria laríngea. Este estado alarmante dura, por lo general, de una a tres horas y después el estado del niño mejora y sólo pers sten los signos de una bronquitis banal. Su repetición es frecuente!.

3. Laringitis subglóticas graves. - Son éstas las lfamadas "laringitis sofocantes" de los autores franceses. Estas fotmas se caracterizan por an edema persistente de la relgión subglótica.

Estas laringitis fueron durante largo tiempo confundidas con la difteria laríngea y no fueton verdaderamente aisladas sino gracias al empleo sistemático de la laringoscopía directa, que permitió un estudio más preciso de las lesionés. Son afecciones muy frecuentes en la práctica pediátrica y entre nosotros es serguramente, la causa común de dísnea aguda laringo-traqueal; pero, por lo general, es diagnosticada erróneamente como "difteria primitiva de la laninge". Muchas veces suelen ser una complicación gripal o de una enfermedad infecciosa general (fiebres eruptivas).

Su iriciación y sintomatología pueden ser idénticas a la de una laring tis estridulosa; pero con la diferencia que eln este caso la sintomatología no cede al cabo de algunas horas, sino que se mantiene largo tiempo en las mismas condiciones. a veces por un mes o. más. Su pronóstico es muv serio, no sólo por el peligro inmeidiato de asfixia, sino también por la frecuencia del las complicaciones puimonares.

La ș:guiente observación es muy característica:

OBSERVACION N. 2. - Fernạndo F.; 11 mrases de edad. Fichx 80116 del Hospital Arriaran

Antecedentes bereditarios y petronales. - Sin Importancis.

Enfermedad actual. - Se inicia el $21-\mathrm{V} l-44$ con ronquera y dificulad respiratoria progresiva, fiebre (380) i tos perrana. Es visto por un pediatra. quien le bace el diagnóstico de difteria y le hace colocar 20,000: unidades de suero antidiftético. Los días sigulentes el nizo contintía en idénticas condiciores y como el 24-VI los sintomas se agraparan, la madre lo lieva a. Ia Poeta Infantil del Hospital Arriarin. Aquí el médico de guardia constata lo siguiente: 
Niño entrófico. Temperaturz $37.7^{\circ}$. Pulso 120. Tiraje snpraesternal discr'te y retracción inspiratoria de los espacios interco:tales. Tos perrunia. Voz slura. Faringe roja. No bay signos de condencasión pulmonar. Diagnostitico probable: laringitis subglótico.

Se deja al nifio hospitalizado en la Posta Infantil con un tratimiento a base de sulfatizzol y antiespasmódicos (atropira-luminall, y c' 26-VI es enviarto a nuestro servicio para examen de la épeialidas.

El examen faringeo y gasal no nos ravala nada de speciai. Al examen waingeo (becho por latingoscopia directa) éncontramos ura discreta hiperemia de las coerdas vocales y edema de la región sutglótica. más acentuzdo 1 inzquierda; no zabia psendomembranas ni ulcezaciones.'

Diagnóstico. - Laringitis sabglótice.

El crameñ y cultivo de la secreción laringé no dió desasrollo de bat cilos de Laeffler.

Continúa el ritio en idínticas condiciones durante tres dias, con tiraje y disnea moderada: pero el 30-VI la disna se agtava brase-mente; aparece cianosis, angustia $y$ estado dz asfixia inninente. por lo cual es intubado tápidamente por el médico de guardia.

Con la intabación, la dificultad respitatoria disminaye y el niño pasa enatro dias en buenas condiciones. El 5.VII. a las 12.45 horas desintuba: queda respirando bien, pero sólo algenos minutos, porque a las 13 horas cat nuevamente con disnea intersa, tiraje, augustiz, cianosis, etc. $y$ tiene que ser reintubado de urgencia:

El 6.VII el niño se mantiene en buenas condiciones, afebril y respirando tranquitamente.

E1 7.VII; a las 5.30 horas, expulsa ei tubo espontáneamente y a raiz de. esto, tiene una crisis inmediata de asfixla." Es traquzotomizatio al instante por el médico de guardia. con lo cual desaparece casi por completo la dificaltad respiratoria: pero a 1as 6.30 horas, en forma sorpresiva, cae en colapso y falkece, no obstante las múltiples tentativas hechas para reanimarlo.

A ia autopsia se encontraron en los pulmones signos discretos de congestó́n. La laringe presentaba edema y ulceraciones de la región subglótica, recubiertas de exudado psendomembranoso. El examen bacteriológico y cultivo 'de estas preudomembranas no reveló la presencia de bacilos de Loeffler, por lo cual se interpretazon como nna consecuencia de las lesiones tranmáticss prodacidas por la lasga permanencia del tubo.

Como podemos ver por la presente observación, que es muy típica, se trata de aféciones de pronóstico muy serio.

4. Laringitis subglóticas circunscritas.-Forma muy rara descrita por Maillard en 1935 (citado por Canut $y$ Lemariev) y de la cual se han señalado muy pocos casos en 
la literatura médica. Se presentaría en el curso de una aferción aguda de las vías respiratorias superiotes, tal como la adenoiditis, por ejemplo.

El cuadro clínico es semejanté al de una laringitis subglótica grave. La lesión se localiza de preferencia a nivel de la pared posterior de la región subgiótica y da origen a un absceso circunscr to que es un verdadero hallazgo broncoscópico.

5. Laringo-tráqueo-bronquitis aguda.-Esta forma ha sido muy bien estudiada y descrita por los norteamericanos, especialmente por Baum (1928), Richards (1933), Ginttens (1938), etc. (citados por Orton).

Esta afección se caracteriza anátomo-patológicamente por edema de la mucosa de la laringe, tráquea y bronquios: con formación de secreciones espesas, adherentes, que al desecarse se transforman en verdaderas costras que obstruyen el lumen respiratorio, dando clínicamente un cuadto de asfixia progresiva. Su pronóstico es grave. Se describe una forma fulminante, una forma asfixiante progresiva y una forma atenuaba. Puede ser una enfermedad primitiva o secundaria a un catarro de la parte alta.

No hay un getmen específico de este cuadro patológico. El dxamen bacterióóg co de la secreción puede revelar la presencia de estreptococo hemolítico, estreptococo viridans, estafílococo, etc., ya sean puros o asociados.

Para lós norteamericanos la laringo-tráqueo-oronquitis aguda seria una entidad patológica bien definica; an cambio. algunos autores franceses, como Lemariev, la consideran sólo una complicación gripal.

También puede presentarse esta afección complicando un cuerpo extraño tráqueo-brónquico, como un caso que tuvimos oportunidad de observar en mayo de 1942 y que fué objeto de una publicación.

En naestro país esta affección es casi destonocida; pero su rareza es probable que no sea tan grande y lo que debe suceder es que no se la reconoce y se la confunde con otras a fecciones, especiaimente con la difteria laringea. Esto.no es raro, porque el diagnóstico de esta enfermedad sólo puede hacerlo con seguridad $e^{1}$ otorrinólogo, que sispone de medios adecuados para e!lo.

En resumen, las laringitis agudas son tal vez, entre nosotros. la causa más frecuente de disnea aguda laringo-traqueal. Lo mismo pudimos observar en la República Argentina durante el invierno de 1943, trabajando en el Servicio de Oto- 
rrinolaringo'ogía de la Sección de Enfermedades Infecciosas del Hospital de Niños de! Buenos Aires. En Norte América sucede, al patecer, algo idéntico; en 1939, por ejemplo. de 226 casos ex disnea aguda laringo-traqueal vistos en el Kingston Avenue Hospital (Brooklyn), por los doctoteis Gilbert, Meyersburg y Silverberg, sóto 16 fueron debidos a difteria laríngea y los 210 restantes. a laringitis agudas no diftéricas (laringit's subglóticas, laringo-tráqueo-bronquitis, etc.).

Causas menos frecuentels de disnea aguda laringotraqueal en la infancia. pueden ser.también la heredo sifitis precoz de la laringe, los papilomas de la laringe y los ábrcesos retro y látero-faringeos.

La heredo sifilis precoz de la laringe produce ronquera y d'snea con tiraje y cornaje, que puede ser agravada por el espasmo. Coexiste, por lo general, con un coriza luético, pénfigo, sifilićels de la piel y mucosas, hipertrofia del hígado, etc. En la sifilis de la laringe se producen lesiones infiltrantes y algunas reces, ulcerosas de la subglotis.

Los papilomas de la laringe se presentan genaralmente en los niños mayores de un año. Provocan ptimero una ronquera persistente $y$ posteriormente aparete la disnea que puede sobrevenir bruscamente. Como veremos más adelante. no constituyel ana dificultad diagnóstica.

Los flegmones y abscesos retro y látero-faríngeos también pueden causar trastornos vocales y disnea, cuando su volumen es considerable. En eistos .casos hay siempre disfagia intensa y es frecuente la adenopatía cervical, tortícolis y rigidez de la nuca.

Tambén pueda prestarse a confusión con una disnea aguda laringo-traqueail, el laringo espasmo. Esta es una afección que no se encuentra sino en los niños menores de dos años y es una de las manifestaciones de la diátes's espasinofílica. El laringo espasmo no es una disnea; es una apnea. Sel presenta bruscamente bajo la forma de una apnea silenciosa, acompañada de estado sincopal con pérdida del conocímientọ. Esta crisis cura sólo algunos segundos y después el niño vueive a la notmalidad.

\section{Diagnóstico de la disnea aguda laringọ-traqueal.}

Salvo casos excepcionales, el diagnóstico por la sintomatología y examen clínico, se presta a muchos errores. En la práctica, los cuadros obstructivos laringo-traqueales, no se 
presentan siempre'con los caracteres elásicos descritos anteriormente. Así, por ejemplo, en una difteria laríngea la voz puede estar clara si las pseudomembranas se encuentran por debajo de las cuerdas vocales; una laringitis subglótica grave puede iniciarsel lentamente simulando una difteria laríngea, etc.

Por lo general, el pediatra en presencia de una disnea aguda laringo-traqueal, anta el temor de desconocer una probable difteria primitiva de la laringe (afección poco frectente), hace el diagnóstico de difteria y coloca una buena dosis de suero al enfermo. A veces por las dudas toma una muestra de la secreción faríngea y la envia al Laboratorio, y después de esto siente a salvo su responsabilidad diagnóstica, creyendo haber hecho el máximo de lo que estaba en su poder. Es muy probable que posteriormente el examen de la secreción no revele la ex:stencia de bacilos de Loeffier, y en tal caso, si se trata de un niño hospitalizado, al colega pediatra el Labotatorio de su. hospital le inspirará profunda desconfianza.

Este proceder no se justifica desde el momento que contamos con un meldio que nos permite el diagnóstico exacto de la afección, rápidamente y sin ningún riesgo para el enfermo. como es el empleo de la laringoscopía directa.

La laringoscopía directa es un procedimiento del examen que permite obtener una visión de la laringe a incluso muchas veces de la tráquea, tan buena como la quet. se puede tener de la faringe con el uso de un bajalengua. Se ocupan para ésto, instrumertos en forma de.espátula, de los cuales hay diversos modelos, como la espátula de Haslinger, de Chevalier Jackson. de Pérez, de Tato, etc. Por su sencillez y por su fáci' manejo, nosotros, en nuestra práctica hospitalaria, preferimos usar indistintamente, los modelos argentinos de Pérez y. de Tato.

La técnica de este examen es muy simple. Se coloca al niño en decúbito dorsal, con la cabeza en hiperextensiốn. Pata impedir sus movimientos se lo envuelve previamente con una sábana. por encima de la cual lo sujeta un ayudante. Otra pelrsona sostiene la cabeza del niño. El operador, provisto de un espejo frontal corriente o de un fronto-lux, introduce la espátula deprimiendo fuertemente la base de la lengua y siguiendo la línea media, hasta alcanzar la epiglotis. Avanza después suavemente el instrumento, levantando la epiglotis con el extremo de la espátula y tiene ante sus ojos una visión perfacta de todo el 'vestíbulo laríngeo, cuerdas vocales, región subglótica y porción superior de la tráquea. Esta ma- 
niobra, para un médico que tenga cierto entrenamiento, sólo demora algunos segundos y no requiere anestesia alguna.

Los distintos cuadros patológicos susceptibles de provocar una disnea aguda laringo-traqueal, aparecen a la laringoscopía directa con sus imágenes características. En la difteria laríngea vemos el vestíbulo de la laringe, cuerdas vocales y región subglótica, tapizadas de falsas membranas. En las laringitis subglóticas la imagen es caracteristica: por debajo de las cuerdas vocales aparecen dos rodetes formados por la mucosa tumefacta, de un color rojo intenso y que producen un gran estrechamiento dell lumen. En la-laringo-tráqueo-bronquitis agtada veremos las secreciones espesas y adherentes que cubren la tráquea y la. ringe. También podremos jercibir la presencia de un cuerpo extraño de la laringe, de ana papilomatosis, etc.

En algunas ocasiones, sin embargo, es necesario recurrit, además, al Laboratorio y a los Rayos X. Por ejemplo, ante una laringitis con pseudomembranas debemos tomar siempre una muestra de la secreción, porque, aunque ratas, se citan ejemplos de laringit:s pseudomełmbranosas no diftéricas, producidas por el estafilococo, estreptoco, etc.

Las disneas por compresión traqueal (adenopatías traquebrónquicas, bipertrofia del timo, etc.) o por obstrucción det un bronquio principal, pueden prestarse a confusión con una disnea aguda laringo-traqueal.

En la disnea por compresión traqueal no hay trastornos vocales y el 'examen por laringoscopía directa es negativo. La dificultad respiratoria, en estos casos, se preseinta en los dos tiempos de la respiración y el niño para aliviar su disnea. inclina la cabeza hacia adelante; al contrario de un niño con obstrucción laringea que hecha la cabeza hacia atrás. La auscultación. la radioscopía y la radiografía harán el diagnóstico en'los casos dudosos; pero conviene no olvidar que si la causa de la disnea es un cuerpo extraño de naturaleza vegettal, no será visible a los Rayos $\mathrm{X}$ y en caso de duôa estará indicada una broncoscopía exploradora.

\section{Tratamiento de $\mathrm{k}$ disnea aguda laringo-traqueal.}

El tratamiento de extrema urgencia ante un niño en petligro de asfixia inmediata por una disnea aguda laringotraqueal de causa desconocida, será ía intubación o la traqueotomía. partiendo de la basel que no hay medios ni tiempo para hacer una laringoscopía directa. En caso que la causa probable sea un cuerpo extraño, debemos decidirnos por la 
traqueotomía antes que por la intubación. y postetiormente, a la brevedad posible, se hará una laringoscopia directa para diagnosticar la causa de la disnea y hacer el tratamiento correspondientel.

El tratamiento causa: consistirá, según la etiología, en la extracción de un cherpo extraño, de una papiloma, sueroterapia antidiftérica, etc. Voy a referirme en especial, sólo al tratamiento de la difteria laríngea y de las laringitis subglóizas graves, que son precisamente las afecciones qual entre nosotros provozan con mayor frecuencia este tipo de disnea y en las cuales. la terapéutica usuà en nuetros servicios hospitalatios, es francamente deficiente comparada con la que se bace actualmente en otros países.

Resumo aquí lo quel observamos durante el año 1943 , en siete meses de estada en la República Argentina, después de haber trabajado en el Hòspital de Niños dé Buenos Aires, en el Servicio de Otorrinolaringología de la Sección de Enfermedades Infecciosas, a cargo de' distinguido éspecialista. profesor Dr. Juan Manuel Tato; y en la ciudad de Rorario de Sarta Fe, con el prestigioso endoscopista, profesor Dr. Manuel González Loza.

Tratamiento de la difteria latingea.-Para facilitar esta exposición distinguíremos el tratamiento medicamentoso, el tratamiento por procedimientos mecánicos y ell tratamiento por medios físicos; aunque, naturalmente, todos ellos se complementan.

a) Tratamiento medicamentoso. - Será de incumbincia casi exclusiva del ped atra y consistirá en sueroterapia a altas dosis, tónicos cardíacos, sedarites dek sistema nervioso. plasmoterapia, hídratación. ette.

No debemos olvidar si, que la administración masiva de anciespasmódicos, en el curso de una disnez aguda laríngea, es peligrosa, porque disminuye el tonus de los músculos respiratorios y pretipita a menudo la asfixia.

b) Tratamiento por procedimientos mecánicos.-Es de enorme importancia y su ejecución estará a cargo del otortinólogo. Consiste principalmente en la extracción instrumenta! o por asp:ración del las pseudomembranas, en la intubación y en la traqueotomía.

Una vez comprobada mejiante la laringoscopia directa, la existencia de pseudomembranas que obstruyen la laringe, debemos proceder inmediatamente a su extracción completa. desprendiéndolas con un porta-algodón y aspirándolas a con- 
tinuación con un aspirador potente. La extracción de las pseudomembranas es siempre una maniobra muy fácil; porque, contrariamente a lo que sucede en la faringe, en la laringe las pseudomembranas no son nunca adherentes y muchas veces flotan en la tráquea y en la luz glótica, como verdaderos cuerpos extraños librels que reproducen a manera de moldes. la forma de estas cavidates.

Con excepción de las pseudomembranas, la difteria no produce en la laringe grandes alteraciones; la mucosa, por Jo general, está ligeramente infiltrada y de un color rojo briIlante, pero sin provocar gran dificultad al paso del aire. La dificultad respiratoria, en estos casos, es provocada exciusivamente por la presencia de las pseudomembranas que obstruyen parcial o casi totalmente la luz de la glotis. La aspiración de las psendomembranas produce inmediatamente una disminución enorme de la disnea. En este séntido, en el Hospital de Niños de Buenos Aires, nos tocó presenciar casos impresionantes de enfermitos que llegaban en tal estado de asfixia, que hacian pensar, a primera vista, en la necesidad inmediata de una intrabación o traqueotomía, y que después de hacerles una aspiración de las pseudomembranas, se pro- Ancía en ellos un cambio rotable: desaparecia la cianosis y su estado de angustia, y la respiración se normalizaba casi por completo.

No ets raro, sin embargo, que algunas horas después de hecha una aspiración completa de las pseudomembranas, éstas vueiven a reproducirse con el peligro de asfixia consiguiente: Esto sucede, especialmente, cuando la dosis de suero ha sido insuficiente. En tal caso deberá repetirse la aspiración las vézes que sea necesario; de aquí la importancia de que estos servicios, en los hospitales de niños, funcionen en forma permanente.

La aspiración de psehdomembranas en la difteria laringea es, en resumen, un espléndido tratamiento, cuyo empleo hace innecesaria, muchas vecess, la intubación o la traqueotomía. No es un tratamiehnto nuevo. Fué dado a conocer, por primera vez, por el norteamericano Linah en $1916^{\circ}$ (citado por Canuyt y O. Tregelles) : posteriormente ha sido empleado con éxito en Inglaterra por $\mathcal{O}$. Tregelles (1933) y por Lemar ey en Francia (1937). En la República Argentina esta terapéutica ha sido introducida $y$ ampliamente difundida. por los doctores Juan Manuel Tato, de Buenos Aires, y Manuel González Loza, de Rosario de Santa Fe. 
La intubación y la traqueotomía dében ser sóio tratamientás de extrema urgencia y para aquellos casos en que rea imposibie recurrir a la aspiración, por falta de tiempo o de ciementos.

La intubación o tubaje, es un procedimiento que tiene muchos inconvenientes. Tal como la practican los pediatras. la intubación es una maniobra ciega y torpe que traumatiza. a menudo, la laringe y es responsable posteriormente, de muchos casos de estenosis cicarticiales irreparábles. El tubo muchas veces sé expulsa espontáneamente-o bien se obstruye. siendo necesaria la traqueotomía de urgencia. Por lo tanto, el niño intubado requiere una constante vigilancia que, en la práctica, sólo es posible en los servicios hospitalarios especializados o elinicas adecuadas para este objeto. El niño intubado, además, se alimenta mal y está expuesto a que los líquidos penetren en la laringet provocando quintas de tos y accesos de sofocación, favoreciendo así la aparición de complicaciones pulmonares.

No deberá dejarse intubado a un niño más de cuatío días y no se empleatá nunca la intubación si existen ulceraciones a nivel de la laringe, por el gravísimo peligro de la estenosis cicatricial que puede producirse en estos cacos. Por esto mismo son muy peligrosas las reintubaciones y sólo deben hacerse conociendo el estado anatómiço de la laringe; . en general, en tal situación, es preferible rekurrir a la traqueotomía antes que a la reintibación.

La intubación tiene también el grave inconvenientel de dificultar el diagnóstico por la laringoscopía directa. Si hacemos, pot ejemplo, con fines diagnósticos, una laringoscopía directa en un niño que ya ha sido intubado, podemos encontrat psetudomembranas no diftér'cas que recubren las erosiones producidas por la permanencia del tubo en la laringe (Observación N." II).

Como dice muy bien Canuyt, la intubación deberia ser sólo una maniobra cestinada a proceder la traqueotomía y hetha con el objeto de quitarle a ésta su carácter de urgencia.

La intubación debería hacerse siempre bajo el control de la vista, o sea, poti laringoscopía directa; operación muyt fácil para el otorrinólogo y que requiere solametnte una pinza porta-tubo especial, romo la ideada por el Dr. Juan Manue! Tato, de Buenos Aires, de la cual tenemos un modelo en nuestro servicio. 
Tratamiento por medios físicos.-Entre éstos mencionaremos el calor, el frío, lá humidificación del ambiente que rodea a estos enfermitos y la oxigenoterapia.

Es clásico colocar a estos niños en un ambiente húmedo y usar localmenté, envolturas tibias; en cambio, algunos autores alemanes, como Schlossmann (citado por Canuyt), prefieren emplear el hielo localmente y colocar a los niños a pleno aire, con lo cual dicen obtener mejores resultados.

La oxigenoterapia, en los casos de disnea intensa y. cianosis, asociada a la aspiración de las pseudomembranas, presta grandes beneficios. Para esta terapéutica existen diversos aparatos: máscaras faciales, tiendas de oxígeno, cámaras de oxígeno, sonda orofaríngea, etc. Las tiendas y cámaras de oxigeno son métodos costosos, complicados y de técnica delicada. Con il sistema de máscaras faciales se pierde mucho oxígeno y Ia cantidad aprovechable resulta insuficiente. El mejor procedimiento $e s$, tal vez, la insuflación orofaringea mediante una sonda a través de la cual se hace pasar, f́n forma constante, día y noche, y por todo el tiempo que fuere necesario, una corrente de oxígeno, en cantidad de 6 a 8 litros por minuto, a una temperatura de $30^{\circ} \mathrm{C}$. y convenientemente saturado de vapor de agua. Esto se consigue con el empleo de aparatos termohumidificadores, de los cuales hay varios modelos: uno muy bueno, tanto por su cómodo manejo como por su precio relativamente reducido, es el ideado por el Dr. Manuel González Loza, de Rosario de Santa Fe, que está bastante difundido en la República Argentina.

La oxígenoterapia debei emplearse en los casos graves desde el primer momento, en forma continua y prolongada, y no dejarse como el últ mo recurso de un moribundo.

Tratamiento de las laringitis subglóticas graves y de las latingo-tráqueo-bronquitis agudas. - En líneas generales, contamos aquí casi con los mismos recursos que para el tratamiento de la difteria laringea.

El tratamiento medicamentoso se hará principalmente a base de la sulfanilamida $y$ de sus derivados, terapéutica con la cual algunos autores, como el norteamericano Graebner. han visto disminuir la mortalidad y la frecuéncia de las complicaciones pulmonares.

La sulfanilamida puede usatse también en estos cuadros infecciosos, localmente, bajo la forma de nebulizaciones. Con esta nueva vía de introducción, los colegas argent nos (Castex. Capdehqurat, etc.) han tenido éxito en el tratamiento de al- 
gunas afecciones broncopulmonares; tales como bronquitis, broquiectasias, etc. Actualmente están ensayando la neubulización de sulfamidas en el tratamiento de las laringitis y laringo-tráqueo-bronquitis agudas. Aunque aún no hay conclusiones definidas al respecto, este tratamiento se presenta altamente promisor y bien valdría la pena hacer, entre nosotros, experiencias en este sentido.

La aspiración es también de gran utilidad en el tratamiento de estos cuadros patológicos, porque, tanto en las laringitis subglóticas graves como en las laringo-tráqueobronquitis agudas, la infección se extiende a menudo a todo el árbol tráqueo-brónquico, originando gran cantidad de exudados, lo que hace que el niño, prácticamente, se abogue en sus propias secreciones. Son éstos los llamados "cuadros de inundación bronquial". La aspiración de las secreciones produce en tales casos una gran mejoría de la disnea; de aquí que sea aconsejable la traqueotomía precoz, no sólo como un medio de evitar el peligro inmediato de asfixia, sino especialmente para poder hacer aspiraciones repetidas de las secreciones, a través del traqueastoma, mediante una delgada sonda de goma que puede introducirse hasta los bronquios. En la laringo-tráqueo-bronquitis aguda este tratamiento puede fracasar dado el carácter especial de las secreciones, que son éspesas, adherentes y se desecan formando costras que constituren verdaderos cuerpos extraños laringo-bronquiales; en tal caso debemos recurrir al tratamiento broncoscópico y retirạr los tapones mucosos y costras, mediante pinzas adecuadas. En esta terapéutica nosotros, en realidad, no tenemos ninguna experiencia. porque, como decía anteriormente, la inmensa mayoría de estos cuadros no son diagnosticados o lo son erróneamente como difteria.

La intubación no es aconsejable en las laringitis subglóticas graves. Resulta insuficiente, muchas veces, porque el edema puede extenderse más allá del extremo đel tu'bo y ademàs, al-introducir et tubo, es muy fácil producir en la zona friable del edema, erosiones extensas que posteriormente da-. rán origen a gtaves estenosis de la laringe.

La oxigenoterapia, en forma prolongada y continua, tal como la explicamos anteriormente al hablar del tratamiento de la difteria laríngea, puede prestar aquí también grandes benef' cios.

Estos enfermitos deben aislarse en boxes adecuados, mantenidos en un ambiente saturado da vapor de agua $y$ a una temperatura de $30^{\circ} \mathrm{C}$. Debe mantenerse sobre ellos una cons- 
tante vigilancia, día $\mathrm{y}$ noche, $\mathrm{y}$ aspirárseles las secreciones todas las veces que sea necesario.

\section{CONCLUSIONGS}

1. Una estrecba colaboración entre el pediatra y el otorrinógolo es indispensable, tanto para el diagnóstico como para el tratamiento de una disßea aguda laringo-traqueal.

2. La disnea aguda laringo-traqueal es siempre una disnea por obstrucción mecánica de la laringe o porción cervical de la tráqueta; ya sea debida a espasmos, cuerpos extraños, secreciones, pseudomembranas, edema, etc.

13 . 'El sintona capital de la disnea aguda laringotraqueal y que por sí solo hace el diagnóstico es el tiraje de la fosa supraesternal y fosas supraclaviculares, que puede extenderse también al hueco epigástrico y espacios intercostales, s: la disnea es muy intensa.

4. El diagnóstico clínico de la disnea aguda laringotraqueal es difícil y tiene un gran margen de error, porque los diversos cuadros patológicos no siempre se presentan con los caracteres clásicos con que se describen. El diagnóstico debe hacerlo el otortinólogo međiante la laringoscopia directa, con el auxil:o, en los casos dudosos, del Laboratorio, Rayos X y examen clínico, hecho por el pediatra.

5. La laringoscopía directa es $u_{n}$ procedimiento de examen que permite ver la laringe y porción superior de la tráquea, en pocos segundos, sin anestesia y sin riesgo alguno para el paciente.

6. En la práctica, las causas más frecuentes de dianea aguda laringo-traqueal son: los cuerpos extraños laringotraqueales, la difteria de la laringel y las laringitis agudas.

7. La difteria primitiva de la laringe es rara. Los pediatras hacen este diagnóstico con excesiva frecuencia y, por lo general, erróneamente y se trata, en tealidad, de laringitis cubglóticas graves o laringo-tráqueo-bronquitis.

8. La aspiración del las pseudomembranas, međiante la laringoscopia directa, es un excelente tratamiento en la difteria laríngea. Hacé, a menudo, innecesaria la intubación o la traqueotomia.

9. La intubación, tal como lo hacen habitualmente los pediatras. es una maniobra ciega, que produce muchas veces, erosiones a nivel de la laringe que pueden dar lugar posteriormente a graves estenos's cicatriciales. 
La intubatción debería hacersel siempre teniendo la laringe bajo el control de la vista, utilizando una pinza portatubo especial.

10. No se hará nunca una intubación en casos de edéma supraglótico o de procesos ulcerosos del la laringe.

11. El niño intubado debe estat sometido a estricta vigilancia; porque el tubo puede expulsarse espontánelimente u.obstruirse con secteciones, ${ }^{3}$ liht grave peligro inmediato de asfixia. , Lix

12. No se dejará nuncosia un niño intubado por más de cuatro días. Si después de desintubarlo persiste la dificultad respiratoria, nos decidiremos por la traqueotomía. Las. reintubaciones son peligrosas porque favorecen la formación de estenosis cicatriciales laringo-traqueales.

13.-En las laringitis subglóticas es preferible recurrir inmediatamente a la traqueotomia antes que a la intubación. La intubación en estos casos puede resultar insuficiente y además, el tubo suéel ocas:onar ulceraciones extensas en la zona del ederna, que es muy friable. La traqueotomía tiene, incluso, la ventaja de permitir hacer aspiraciones repetidas de la secreción laringo-traqueal, a través del traqueostoma, usando para esto una delgada sonda de goma; procedimiento muy empleado por los norteamericanos.

14. La oxigenoterapia, por sonda orofaríngea, es un valioso recurso en el tratamiento de la difteria laringea y laringit's subglóticas graves. Debe emplearse en forma continua y prolongada, precozmente, y no dejarse 'como un último recurso.

15. La sulfanilamida y sus derivados parecen tener una acción favorable en el tratamiento de las laringitis subglóticas graves y laringo-tráqueo-bronquitis; disminuirían la mortalidad y la frecuencia de las complicaciones pulmonares.

\section{Bibliografia.}

1.-BOYLAN ORTON, ELLIS SMITH. H. BELL' and R. FORD.. "Acute laryngotracheobronchitis". Arch. of Ot. 1941. N." 6, p. 926.

2.-CANUY'T G. - "Les maladies-da larnx". Paris, 1939.

2.-CAPDEHOURAT E. - "Procesos de las vías respiratorias que benefician con las nebulizaciones". El Día Médico. Buenos Aires. 1944. N. 22, p. 545.

4. CASTEX M. - "Contribución al tratamiento di los procesos sufuvativos broncopulmonares mediant: las sulfainidas nebuivadas". Frimer Congreso Nacional de Medicina. 1942. Santiago da Chile. 
'5.-GLLBERT J., H. MEYERSBURG and J. SILVERBERG. - "Croup. - Preliminary report on one year's investigation of two hundred and tweaty-rix cases". Arch. of Ot. 1941. N.8 2. p. 281.

-6.-CONZALEZ lOZA M. y J. M. TATO. - "La directoscopia en el diagnóstico $\mathrm{g}$ en el tratamisto de ta difteria laringo-traqueal". Andles de O. R. L. dei Uruguay. 1940. T.X. P. i.

7.-GONZALEZ LOZA M. - "Tratamiento endoscópico del -crup diriterico" Rev, Arg. de D. R. L. 1941 . N.9 2. p. 163.

8.-GONZALEZ LOZA M. - "Laringo-tráqueo bronquitis agrda asfixiante". Semana Médica. Bupnos Aires. 1942 . N. ${ }^{9}$ 2, p. 5.

9.-GONZALEZ LOZA M. - "Crup. Concepto endoscópico Y. terapúutice": Rev, de O. R. Li. del Litoral, 1942. N.9 2, p. 154.

10.-GONZALEZ LOZA M. - "Termohumidificador pata carbq y oxigenotzrapia" Rev. de O. R. L. del Litoral. 1942. N.9 2, p. 163.

11.-GONZALEZ LOZA M. - "La oxigenoterapis como tratamiento de elección de las hipolaringitis obstruttivas agudas de la infancia". Rer. Arg. de O. R. L. 1941 . N.os 1-2, p. 61.

12.-GRAEBNER H. - 'Chemotherapy in acute nondiphteric laryngotratbecobronchitis". Arch. of Ot. 1942. N. 4. p. 523.

13.-LATORRE A. - 'Etrotes de diaznóstico que pueden ocasionar lat complicaciones de los caerpos extraños tríqueo+brónquicos". Rev. de O. R. L. (Santiago de Chile) 1942. N.9 3, p. 120.

14.-LEMARIEY A. - - "Les dyspnérs: aigues laryngés et laryngo-tracbéales de l'enfance", Les Ann. d'Ot. 1937. N. 5. p. 377.

15. - LE MEE J. M.. BLOCH M. BOUCHET M. - "Les inflammations aigües de l'hypolarynx chez l'enfant". Les Ann. d'Ot. 1938. N.9'10.

- p. 1003.

16.-TREGELLES 0 . - "The Aspiration Treatmeat of haryngeal Diphteria". The British J: of Children's Diseases. 1932. Vol, XXX, p. 97. 